\title{
Yves Klein en Madrid. La fragua de un artista*
}

\author{
Irene LÓPEZ ARNAIZ \\ Universidad Complutense de Madrid \\ Departamento de Historia del Arte III (Contemporáneo) \\ irenelarnaiz@gmail.com
}

\section{RESUMEN}

Yves Klein realizó dos estancias en Madrid en 1951 y 1954 y entre ellas un viaje a Japón. Durante estos años los intereses del futuro artista se centraron en el judo. Sin embargo, poco antes de abandonar la capital española en 1954 Klein realizó su primera obra de arte, Yves Peintures, dando así un giro un tanto inesperado a su vida. Por este motivo, resulta de gran interés analizar los lugares comunes entre los principios estéticos de sus obras y los fundamentos del judo tradicional, cuyas bases se asientan en la filosofía Zen. Conceptos como el vacío, la inmaterialidad, el infinito, o la propia espiritualidad, esencia misma del arte de Yves Klein, deben entenderse desde la filosofía oriental puesto que son nociones que impregnan también ese arte marcial.

Palabras clave: Madrid; Tokio; judo; Zen; Yves Peintures.

\section{Yves Klein in Madrid: Forging an Artist}

\begin{abstract}
Yves Klein lived in Madrid during two periods of time, in 1951 and in 1954, and travelled to Japan in between these years. During this interval the interests of the artist-to-be were centred on Judo. Nonetheless, before leaving the capital of Spain in 1954, Klein created his first piece of artwork, Yves Peintures, which constitutes a quite unexpected turn of events in his life. For this reason, it is very interesting to analyze the common ground in between his aesthetic principles and the fundamentals of traditional Judo, the foundations of which are set on Zen philosophy. Concepts such as emptiness, immateriality, infinitude or even spirituality, the very essence of Yves Klein's art, must be understood from the perspective of Eastern philosophy given that they are notions that permeate this martial art.
\end{abstract}

Key words: Madrid; Tokyo; Judo; Zen; Yves Peintures.

\footnotetext{
${ }^{*}$ Las últimas revisiones de este trabajo con vistas a su publicación han sido realizadas gracias a un contrato predoctoral del MINECO-UCM, vinculado al proyecto I+D+i HAR2012-22462 "Trama" ("Transculturalidad, mestizaje y mundialización: aproximaciones interdisciplinares teórico-prácticas del arte contemporáneo. Oriente-Occidente").
} 


\section{Introducción}

Los años de juventud de Yves Klein, poco conocidos por considerarse muy alejados de cuestiones artísticas, resultan fundamentales para el estudio de su obra. A pesar de que sus padres, ambos pintores, podrían haberle facilitado el camino en el terreno artístico, sus intereses juveniles se centraron en el judo y en el descubrimiento de diversos lugares del mundo. Realizó numerosos viajes que le proporcionaron experiencias y enseñazas que supo guardar a buen recaudo hasta que encontró el momento oportuno para adentrase en el terreno del arte.

Fue en Madrid donde Klein realizó Yves Peintures, una obra en papel que recoge con cierta sutileza sus vivencias en ese gran viaje hacia la madurez personal y artística. Una obra que anuncia también con gran originalidad, de un modo irónico y absolutamente enigmático, toda una propuesta artística que presentará gran coherencia desde sus comienzos y en la que la presencia del judo y de la filosofía oriental ocuparán un lugar muy destacable. De este modo, la ciudad de Madrid, esta primera obra de arte y el judo como vía de meditación del Budismo Zen, se convierten en factores esenciales para el estudio del complejo trabajo artístico desarrollado por Yves Klein a lo largo de toda su carrera artística.

\section{El descubrimiento del mundo. Madrid un lugar clave}

"Madrid, la hermosa ciudad, poseedora del alegre París y del monstruoso Londres, hermosa, espléndida, con grandes y largas avenidas pero en la que por todas partes tenemos la impresión de teatro, todo el mundo interpreta un papel y todo es decorado teatral"', escribía Yves Klein nada más llegar a la capital española al comenzar el año 1951. Las dos estancias de Klein en Madrid en 1951 y 1954 forman parte de unos años de juventud en los que la indecisión y cierta desorientación parecen ser los protagonistas. Con diecinueve años, Klein había comenzado a practicar judo en Niza, un pasatiempo que cada vez irá cobrando más importancia en su vida hasta hacer de él un deportista de élite. Sin embargo, al mismo tiempo, esa indecisión juvenil le llevó a planear estancias en diversos lugares del extranjero entre los cuales Madrid ocupará un lugar fundamental, una suerte de gran aventura que le conducirá hacia la madurez personal y que terminará por introducirle, contra todo pronóstico, en el ámbito artístico².

Yves Klein consideró a menudo que esta aventura comenzó realmente en Inglaterra e Irlanda, lugares donde residió durante unos meses en compañía de su amigo Claude Pascal entre 1949 y 1950. Allí continuó practicando judo, se preocupó por

1 Entrada del diario de Yves Klein (inédito, Archives Yves Klein), 4 de febrero de 1951, Madrid, primer cuaderno, original en francés, p. 9. En todas las referencias al diario de Yves Klein se seguirá la paginación del manuscrito original.

2 Para el estudio de estos años de juventud de Yves Klein, de las estancias en Madrid y de los inicios de su actividad artística, se remite al lector al texto ARNALDO ALCUBILLA, Javier, "Yves: el viaje a España", en Marie Raymond. Yves Klein. Herencias, catálogo de exposición (Octubre 2009 - enero 2010), Madrid, Circulo de Bellas Artes, 2009, pp. 19-37. 
aprender inglés e incluso recibió clases de equitación, pues entre sus planes se encontraba llegar a Japón a caballo con sus amigos Pascal y Armand Fernández ${ }^{3}$. Amigos a los que había conocido en los cursos de judo que había iniciado en Niza y junto a los que se matriculó en los mismos años en un curso a distancia de la Sociedad Rosacruz de Oceanside ${ }^{4}$. Los tres pretendían llegar a Japón pasando por España y Marruecos, lugar en el que esperaban conseguir caballos a precios muy asequibles ${ }^{5}$. Estos planes de viajes tan extravagantes evidencian la curiosidad que siempre manifestó Klein hacia otras costumbres y lugares del mundo, así como esa idea romántica de ir a Oriente con la intención de descubrir culturas "exóticas"6.

Como era de esperar, por diversas circunstancias, las cosas no ocurrieron según lo previsto, pues Pascal cayó enfermo y Arman no podía dejar sus obligaciones en Francia. Finalmente, Klein decidió viajar a Madrid y continuar con su aventura en solitario. Tras recibir clases de español durante un mes, en febrero de 1951, cogió un tren con destino a la capital española. Sus principales objetivos eran aprender español y continuar practicando judo, aunque la curiosidad por las costumbres y el arte español se hizo también muy presente. Realizó excursiones a La Granja, Toledo y El Escorial, visitó el Museo del Prado, descubrió la Semana Santa madrileña, las corridas de toros y acudió a espectáculos de flamenco de Lola Flores y Manolo Caracol. Muchas de estas cosas las hizo en compañía de su amigo Joaquín, un estudiante de letras que le introdujo en muchas de las costumbres españolas y que parece una figura fundamental en esta primera estancia madrileña. Le ayudó a aprender español llegando incluso a corregirle las anotaciones que hizo en su diario y hasta le animó a pintar, pues Klein debía hablarle a menudo de sus incipientes, sutiles y enigmáticas incursiones en el ámbito de la pintura ${ }^{7}$. Todas estas vivencias quedaron magníficamente recogidas en

3 Se trata del artista Arman. En adelante se le hará referencia con su nombre artístico.

4 Terminaron por adherirse a esta sociedad en 1948, ese mismo año Klein descubrió un ejemplar de la Cosmogonía Rosacruz de Heindel en la librería de su tía Rose en Niza. Durante algunos años Klein participó de manera activa en esta sociedad, recibía lecciones sobre las que trabajaba a diario para enviarlas finalmente a Ocenside. En su diario de Madrid de 1951 anotó a menudo sus reflexiones a raíz de los pasajes del libro de Heindel que seguía leyendo y de las lecciones que desarrollaba.

5 Klein anotaba en su diario de Irlanda: "Conocemos ahora lo suficiente como para estar algunos minutos en un caballo, pero esto quizás no sea suficiente para la idea viajar a caballo a Japón” (inédito, original en inglés); en ROSENTHAL, Nan, "La lévitation assistée”, en Yves Klein, catálogo de exposición (marzomayo de 1983, París), Paris, Centre Georges Pompidou, 1983, p. 199. Vid. también el texto de KLEIN, Yves, "L'aventure monochrome: L'épopée monochrome, en KLEIN, Yves, Le dépassement de la problématique de l'art et autres écrits (ed. de Marie-Anne Sichère y Didier Semin), Paris, École Nationale Supérieure de BeauxArts, 2003, pp. 242-243: "Yo había salido para Inglaterra de repente con mi amigo de Niza, Claude Pascal. Juntos habíamos decidido estudiar dos idiomas, inglés y español, residiendo en los países correspondientes. Queríamos partir después juntos a caballo hacia Japón por el judo. Saldríamos de España vía Marruecos, donde por entonces era posible hacerse con caballos a precios muy asequibles".

6 En su diario de Madrid de 1951 recoge además la idea de trabajar en Bagdad por un periodo de tres años en compañía de Claude Pascal, así como de un posible viaje a Egipto, Persia e India.

7 Klein anotaba en su diario madrileño: "Joaquín ha insistido tanto que he empezado a pintar pero previniéndole que mi pintura (si se puede llamar pintura) no le gustará. En efecto le desilusionó y para reparar la desastrosa impresión hecha, debí pintar rápidamente una acuarela de Toledo según una tarjeta; eso más realista le agradó". Entrada del diario de Yves Klein (inédito, Archives Yves Klein), 25 de febrero de 1951, Madrid, segundo cuaderno, original en castellano, pp. 10-11. Se conserva una acuarela de la vista de la ciudad Toledo realizada por Yves Klein que podría corresponderse con la que describe en este pasaje. 


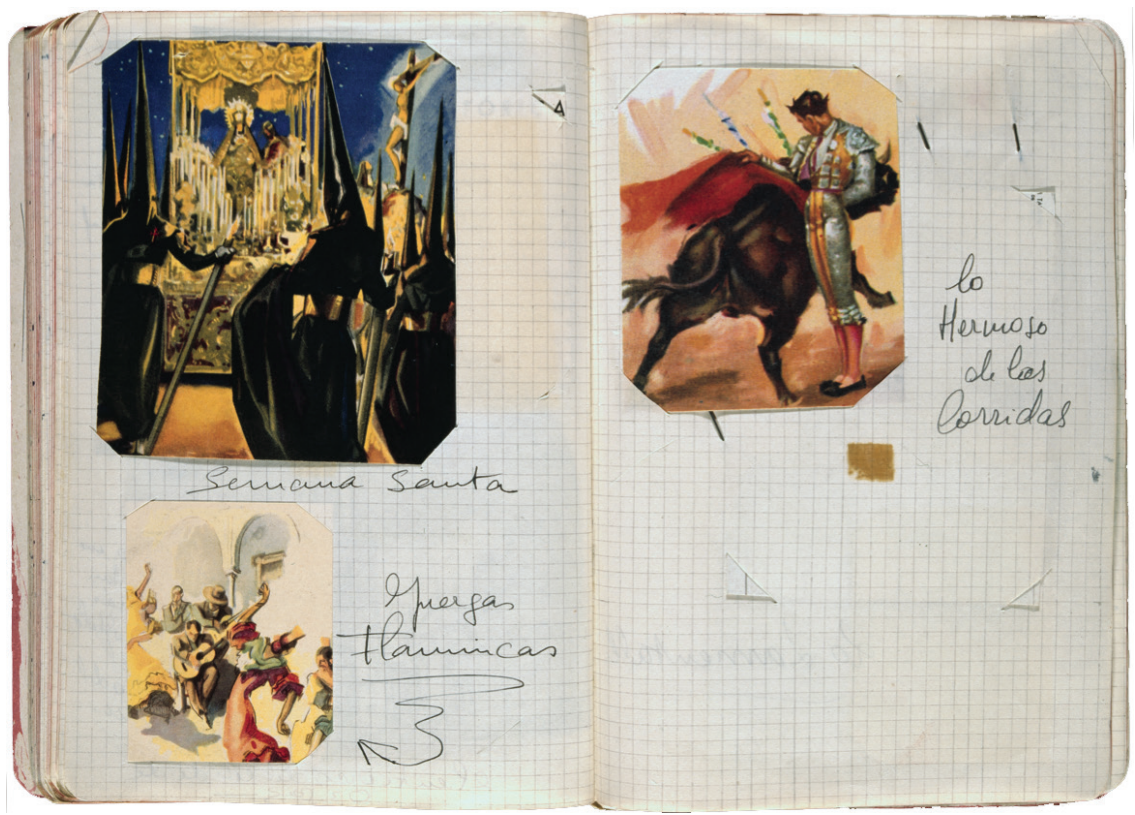

Fig. 1. Yves Klein. Pages du Journal d'Espagne, 1951. C Yves Klein, Adagp, Paris, 2014.

su diario a través de numerosas anécdotas, fotografías y acuarelas de aquellas cosas que le llamaron más poderosamente la atención (fig. 1).

Al poco tiempo de llegar a Madrid, Klein encontró uno de los pocos clubes en los que se podía practicar judo en Madrid, el Bushidokwai, que todavía por aquel entonces se encontraba en la Calle Recoletos ${ }^{8}$. Pasados unos meses le ofrecieron ocuparse de las clases de uno de los profesores y Klein, que llevaba un tiempo desesperado buscando trabajo, accedió entusiasmado. Entabló cierta amistad con los dueños del gimnasio, especialmente con Fernando Franco Sarabia que tras su partida en el mes de junio, le propondrá a menudo regresar a Madrid para volver a impartir clases en su club.

Entre las dos estancias de Klein en Madrid se sitúa ese destino lejano que parecía una gran utopía, la ciudad de Tokio, lugar al que se dirigió en septiembre de 1952 y donde residió durante quince meses. Llegó a Japón con la intención de conocer las bases del judo tradicional, estudió en el reputado Instituto Kodokan hasta lograr el título de Cuarto Dan después de largos meses de intenso trabajo y esfuerzo (fig. 2). Tras esta prolongada estancia en Japón, Klein regresó a Francia esperando ser reconocido como uno de los grandes judokas europeos. Parecía que finalmente había encontrado su camino en el terreno del judo y estaba dispuesto a cosechar grandes

8 Poco tiempo después fue trasladado al 61 de la Calle Donoso Cortés. El gimnasio se conserva todavía hoy en el mismo sitio aunque la numeración de la calle ha cambiado, la dirección actual es Calle Donoso Cortés $n^{\circ} 53$. 


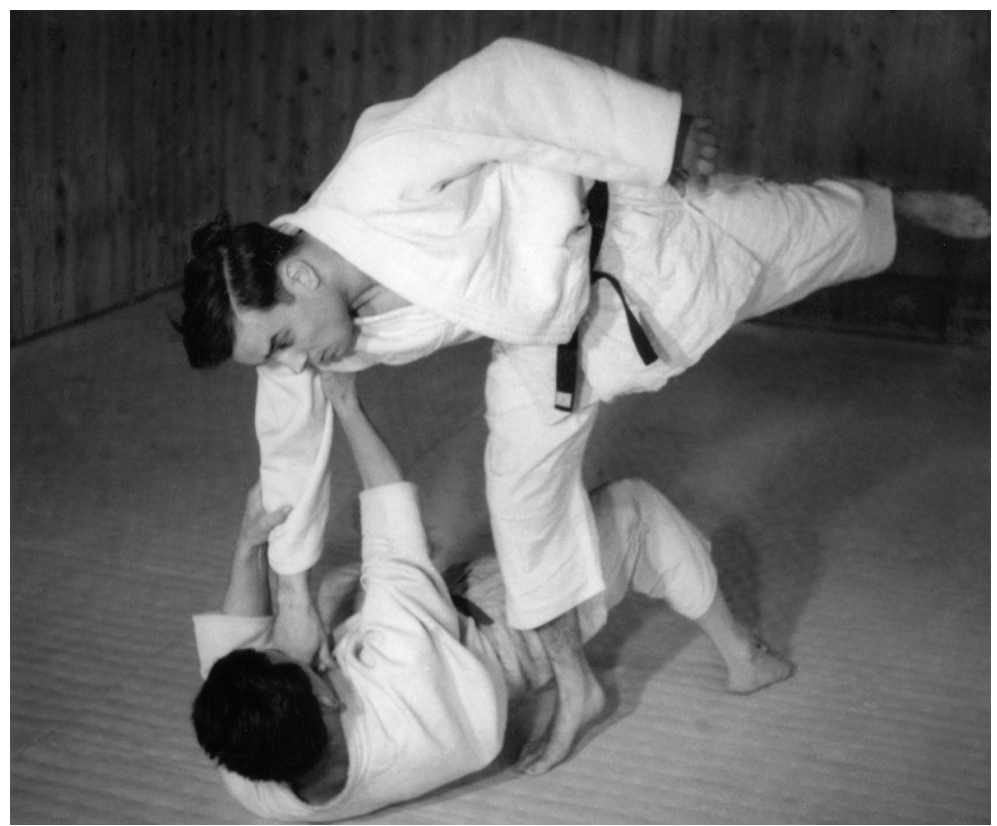

Fig. 2. Yves Klein et maître Asami, Koshiki-no-kata, Tokyo, Japon, 1953. C Yves Klein, Adagp, Paris, 2014.

éxitos, pero se encontró con la amarga desilusión de que sus compañeros franceses no le reconocían el título obtenido en Japón. Aquel triunfante recibimiento que imaginaba desde la capital nipona se convirtió nada más llegar a Europa en celos y envidias por parte de los judokas franceses que no le permitieron ni siquiera competir en sus propios campeonatos.

A pesar de todo Klein no se daría por vencido, puesto que en Francia no le reconocían sus logros, probó suerte en el lugar donde había comenzado a ganarse la vida con el judo, la ciudad de Madrid. En la primavera de 1954, Klein aceptó la reiterada propuesta de Franco Sarabia de regresar al Bushidokwai como profesor ${ }^{9}$. Además fue nombrado Asesor Técnico de la Federación Española de Judo, convirtiéndose así en el máximo responsable a nivel nacional de este deporte y del equipo español al que llevó al campeonato europeo que aquel mismo año tuvo lugar en Bruselas ${ }^{10}$.

9 Véase la carta que Klein dirigió a Fernando Franco Sarabia, inédita, sin fecha Paris, Archives Yves Klein (original en castellano): "Fernando quédate seguro de esto que yo quiero ir a España enseñar el Judo más que todo y más que todo también te enseñaré a ti lo más posible y gratis [sic.]”.

10 La fecha en la que obtuvo dicho cargo parece algo confusa, se conserva un documento firmado por Fabián V. del Valle, fechado el 21 de mayo de 1954 en el que se nombra a Yves Klein asesor técnico de la Delegación Española de Judo por un periodo de cuatro años. Sin embargo, con fecha de 11 de noviembre de 1953 se le otorgó una acreditación como asesor técnico emitida por el Comité Olímpico Español (Archives Yves Klein). Por aquel entonces Klein se encontraba todavía en Japón y parece que, con la intención de lograr la obtención del Cuarto Dan que tanto se le estaba resistiendo, solicitó a la Federación Española dicho 
Hacia el mes de mayo de 1954 Yves Klein regresaba a Madrid con las cosas aparentemente más claras que aquella primera vez a comienzos de 1951. Se había convertido en un judoka de alto nivel y parecía dispuesto a luchar por el reconocimiento que consideraba merecido. Conocía las bases del judo tradicional y se propuso dar a conocer en Europa los fundamentos de este arte marcial, ya que la técnica que imperaba en el continente era la introducida en Francia por Kawaishi adaptando el judo al espíritu occidental. Sus alumnos de entonces señalan todavía hoy la novedad de algunos de los ejercicios de Klein así como la destacable labor que llevó a cabo en el desarrollo del judo español ${ }^{11}$.

Parecería como si aquel joven francés, hijo de pintores, por fin hubiera encontrado en el judo su verdadera vocación tras aquellos años en los que había estado huyendo del terreno artístico al que pertenecían sus padres como una especie de revulsivo adolescente. Había trabajado muy duro para formarse en este arte marcial y comenzaba por fin a alcanzar importantes méritos. Aquella especie de viaje iniciático que había comenzado cuatro años atrás sin un claro rumbo ni objetivo parecía acercarse a su fin puesto que había logrado afianzarse como el máximo responsable del judo español. Sin embargo, justo antes de abandonar Madrid a finales de 1954, sus intereses cambiaron de rumbo de modo sorprendente al realizar en la imprenta de Franco Sarabia Yves Peintures ${ }^{12}$. Ya en esta primera obra, Klein conjugó los fundamentos del judo tradicional y los fundamentos del Zen que había descubierto en Japón, tal y como haría en cada una de sus propuestas artísticas posteriores.

\section{Del Judo al Arte: "el espíritu de los deportistas es abstracto" 13}

En Japón Klein había entrado en contacto con el judo tradicional, comprendió y asimiló la esencia del verdadero judo y se sumergió de lleno en la práctica del Zen. La palabra judo podría traducirse como camino o vía de la suavidad o flexibilidad. Así lo entendió Klein, como un arte místico y flexible, vía de meditación y camino de la espiritualidad y no como un simple deporte en el que demostrar fuerza y violencia. Klein recordaba desde Tokio sus primeros contactos con el judo en Francia:

"De la noche a la mañana dos nuevos profesores cambiaron el método del entrenamiento brutal a un pequeño grupo de Jiu-Jitsu y enseñaron judo. [...] Ya no era cuestión de fuerza bruta sino de arte flexible, la vía de la suavidad, traducción literal de la palabra japonesa. [...] Sólo pensaba en los fantásticos movimientos del judo que gracias a

\footnotetext{
nombramiento con la intención de que los japoneses percibieran el reconocimiento internacional que poseía Yves Klein.

11 Entrevista de Irene López con Félix Arrivas (alumno de Klein en Madrid en 1954), Madrid, 4 de abril de 2011.

12 Klein realizó dos obras diferentes: Yves Peintures y Haguenault Peintures que, aunque similares, guardan algunas diferencias destacables entre sí. De aquí en adelante se hará referencia a ambas con el nombre de Yves Peintures, exceptuando los casos en los que se pretenda recalcar las diferencias entre dichas versiones.

13 En 1954 Yves Klein escribió un texto sobre judo con el título L'esprit des sportifs est abstrait (El espíritu de los deportistas es abstracto). Dicho texto permanece inédito, el manuscrito se conserva en los Archives Yves Klein.
} 
la técnica 'traspasaban la fuerza del adversario para proyectarlo fácilmente', permitían vencer al adversario empujándolo con el mínimo esfuerzo" 14 .

Fue este aspecto místico del judo lo que debió interesar a Klein desde el principio, por ello llegaría posteriormente a conjugarlo incluso con sus obras de arte. Durante los primeros años de la década de los cincuenta aparentemente Klein no podía estar más alejado del ámbito artístico pues estaba centrado en el judo, su filosofía y las teorías de la sociedad rosacruz. Sin embargo, poco tiempo después, sacaría a la luz toda una propuesta artística cuyas bases parecen claramente deudoras del judo y por consiguiente muy ligadas a la filosofía oriental. Klein reconoció mucho después que siempre había sido artista, pero que tomó consciencia de ello cuando encontró en el arte el camino para hacer visible la espiritualidad del judo. Así lo defendió:

'He luchado contra mi vocación de 'pintor' partiendo a Japón para vivir la aventura del judo y las artes marciales antiguas, también he luchado contra mi vocación de 'hombre de teatro'; pero precisamente el judo por la práctica física y espiritual de los $k_{a t a}{ }^{15}$ ha constituido mi formación en esta disciplina del arte que es el teatro" ${ }^{16}$.

Klein encontró en la práctica física y espiritual del judo la esencia de su arte, esa sensibilidad pictórica inmaterial que persiguió con vehemencia y que llegó incluso a ofrecer al espectador a través de sus obras. Entendió el judo y el arte como experiencias similares, puesto que ambas actúan a través del cuerpo, aunque en ellas ni el cuerpo físico ni la técnica permiten la maestría, sino que lo hace el trabajo con el interior. Es en esta espiritualidad donde se fusionan sin dificultad el judo y el arte de Yves Klein. Así lo explicaba él mismo: "la práctica del judo hace comprender que el espacio pictórico es ante todo el fruto de un acceso espiritual: el judo en efecto, es el descubrimiento por el cuerpo humano de un espacio espiritual" ${ }^{17}$. Klein insistió en la importancia de practicar el judo en "espíritu y sensibilidad pura" ${ }^{18}$, dos términos que aplicó a menudo a sus propuestas artísticas.

También el ritual, muy próximo a las tradiciones del budismo, estuvo muy ligado a la concepción artística de Yves Klein. De este modo deberíamos entender obras fundamentales como sus antropometrías ${ }^{19}$ (fig. 3). El propio artista lo explicaba:

\footnotetext{
14 Anotación escrita por Yves Klein en Japón, junio de 1953, Archives Yves Klein, en OTTMANN, Klaus, Yves Klein le philosophe, Paris, Éditions Dilecta, 2010, p. 97.

15 El método del Kodokan sentaba las bases del judo en la ejecución de los kata. Estos movimientos conforman un código gestual muy complejo que el judoka debe seguir minuciosamente en cada combate. Sin duda hay que conocer los kata para llegar a la esencia del judo. En origen había seis kata y actualmente se han añadido otros dos tipos. Jigoro Kano, el fundador del Kodokan, defendía: "los kata son la estética del Judo. En los kata (formas) se encuentra el espíritu del judo sin el cual es imposible llegar al fin". Palabras de Jigoro Kano en KLEIN, Yves, Les Fondaments du Judo (1954), Paris, Dilecta, 2006, (sin paginación).

16 KLEIN, Yves, "La guerre", en Dimanche. Le journal d'un seul jour, Festival d'Art d'Avant-garde, Paris 27 de noviembre de 1960, número único publicado en Presse de Combat, p. 3. Se conserva un ejemplar original en la Biblioteca del Museo Nacional Centro de Arte Reina Sofía.

17 KLEIN, Yves, texto sin título, en OTTMANN, Klaus (2010), op. cit., p. 127.

18 Vid. KLEIN, Yves, "Réflexions sur le Judo le Kiai, la Victoire constante", en KLEIN, Yves (2003), op. cit., p. 370 .

19 La más destacable tuvo lugar el 9 de marzo de 1960 en la Galerie nationale d'art contemporain de Paris.
} 


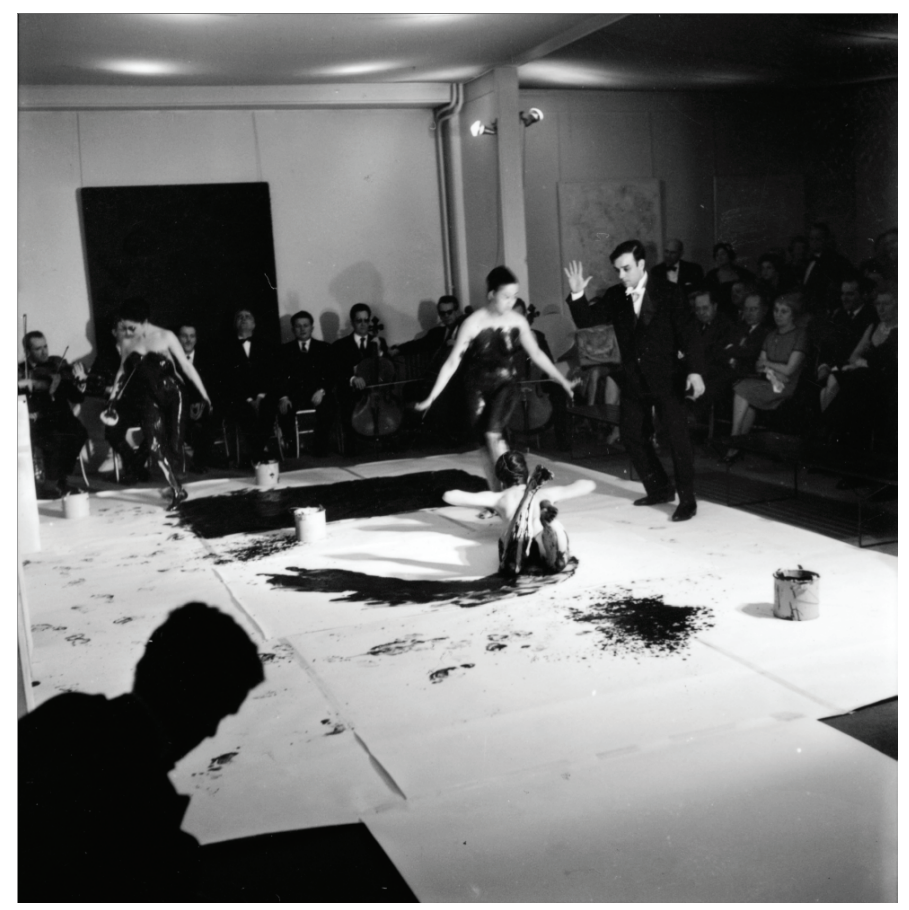

Fig. 3. Yves Klein. Action artistique Anthropométries de l'époque bleue, Galerie Internationale d'Art. Contemporain, Paris, 9 mars 1960. C Yves Klein, Adagp, Paris, 2014 Photograph: Shunk-Kender (C) J. Paul Getty Trust. The Getty Research Institute, Los Angeles (2014.R.20).

"El día que comprendí que los tiempos del pincel habían terminado, que al fin mis conocimientos de judo iban a resultarme útiles, mis modelos fueron mis pinceles [...]. Combiné una especie de ballet de chicas manchadas sobre una tela que parecía un tapiz de combate de judo" 20 .

Klein se centraba en el cuerpo de sus pinceles vivientes, dirigía minuciosamente cada uno de sus movimientos, precisaba de horas de preparación para finalmente ejecutar las obra en sólo unos minutos, tal y como ocurre en los combates de judo. Pero tan sólo a través de esos movimientos profundamente calculados, el artista lograba manifestar la energía cósmica inmaterial. La huella de la filosofía Zen en esta obra parece clara, al igual que en aquella celebre anécdota que cuenta como Hokusai empleó un pollo con las patas manchadas de bermellón para pintar Hojas de otoño cayendo sobre el río Yangtze.

Elena Palumbo, una de las modelos que Klein empleó para sus antropometrías, describía del siguiente modo su experiencia:

20 KLEIN, Yves, en DESCARGUES, Pierre, Yves Klein, "L'homme qui a vendu du vide", en Tribune de Laussanne, 1960, recogido en OTTMANN, Klaus (2010), op. cit., p. 435. 
“Cuando trabajábamos en el 'taller' elaborando las Antropometrías, parecía definitivamente una especie de ceremonia: la modelo estaba físicamente impregnada de Azul Klein (IKB), en silencio, en una atmósfera muy intensa: Yves [...] sólo indicaba dónde debían aplicarse los colores. Cuando el cuerpo de la modelo se impregnaba de azul quedaba definitivamente transformado en una energía vital materializada; parecía convertirse en un medio para que fluyera la energía ki”"21.

Tal y como señala Anna Follo, el ki representa la fuerza vital que fluye en los organismos generando procesos fisiológicos como por ejemplo la respiración, la digestión, o la circulación de la sangre ${ }^{22}$. En un combate de judo el vencedor no será en ningún caso el más fuerte, sino aquel capaz de acumular y dirigir su propio ki, que finalmente quedará transformado en energía espiritual.

En las antropometrías Klein dirigía minuciosamente los movimientos de sus pinceles vivientes con la intención de que terminaran por manifestar la energía cósmica inmaterial. Y lo logró por la distancia física que mantuvo con estas obras, pues no era él el que pintaba sino los cuerpos de las mujeres. Esa distancia le permitiría esa unión con el vacío que Klein persiguió durante toda su vida. Con ese mismo vacío que debían generar ambos combatientes: tori y uke (el que desencadena y el que recibe el movimiento respectivamente), ese vacío intermedio que permitirá a uno apoderarse de la energía del contrario para lograr vencer. Klein entendió el judo y su propio arte en función de la noción de vacío en el sentido oriental, ese vacío originario hacia el que todo ser humano debe tender, base del pensamiento taoísta. Este vacío, esencia del judo, es una promesa de plenitud pues hace posible en su negatividad la aparición de una existencia. En ese camino o vía - do- que es el judo, se contienen los complementarios del pensamiento taoísta, el yin y el yang, representados por el uke y el tori. Estos dos principios no se encuentran en oposición sino que, habitados por ese vacío intermedio, se sitúan en un proceso de interacción muy similar al generado en un combate de judo ${ }^{23}$.

El uso de un solo color en sus obras monocromas, como el de una sola nota en su temprana Sinfonía Monótona Silencio, crea un sentido de infinito muy cercano al que se pretende alcanzar a través del judo. Klein conjugó en su arte y en su propia vida principios aparentemente contradictorios pero que entendidos desde una concepción oriental se complementan llegando a necesitarse el uno al otro para terminar de existir. El pigmento puro de sus monocromos es material e inmaterial al mismo tiempo, pues termina por constituirse como una presencia física y real de lo invisible e inmaterial. Del mismo modo que esa sinfonía de una sola nota se convierte, en su continuidad, en silencio. Siguiendo este planteamiento, Klein expuso El Vacío ${ }^{24}$ "para recibir

21 PALUMBO MOSCA, Elena, "Su Yves", cit. en FOLLO, Anna, "Monochromy, void and Kata: ongoing references to the Orient in Yves Klein's oeuvre”, en CORÀ, Bruno y MOQUAY, Daniel (eds.), Yves Klein, catálogo de exposición, Milan, Silvana Editoriale, 2009, pp. 42-43.

22 FOLLO, Anna, "Monochromy, void and Kata: ongoing references to the Orient in Yves Klein's oeuvre", en CORÀ, Bruno y MOQUAY, Daniel (eds.) (2009), op. cit., p. 43.

23 En relación con la noción de vacío, vid. CHENG, François, Vide et plein, Paris, Editions du Seuil, 1991.

24 Exposición La spécialisation de la sensibilité à l'état matière première en sensibilité picturale stabilisée, Le Vide (époque pneumatique) en la Galerie Iris Clert, Paris, 1958. 


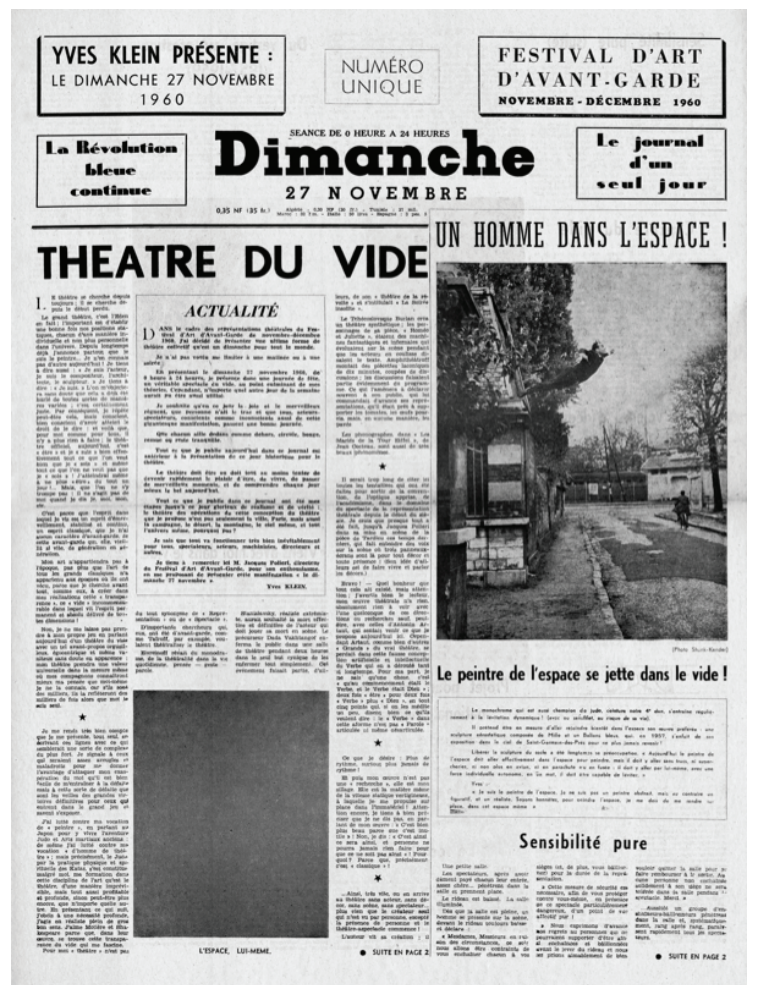

Fig. 4. Yves Klein. Dimanche. Le journal d'un seul jour, (IMMA 36), 27 novembre 1960, (C) Yves Klein, Adagp, Paris, 2014.

la sensibilidad del azul inmaterializado"25; 1lenando con su propia presencia ese vacío que él mismo había creado vaciando la galería y pintándola de blanco, Klein logró la inmaterialidad del pigmento puro, logró bañar, zambullir -en el sentido físico- al espectador en la pura inmaterialidad del pigmento ${ }^{26}$.

Yves Klein, mediante toda su propuesta artística logró proveer a algo tan material como es la pintura, de una inmaterialidad propia del estado último de liberación. Pero lo hizo empleando siempre elementos materiales y orgánicos que no hacen sino remitirnos al ámbito de las sensaciones. Utilizó el pigmento puro, el oro, el fuego, el agua y los cuerpos de las mujeres para ofrecer al espectador un baño de sensibilidad pictórica inmaterial, un baño real en el que sumergirse con la intención de que experimente sensaciones similares a las que deben sentirse en un combate de judo.

25 KLEIN, Yves, "Le dépassement de la problématique de l'art", en KLEIN, Yves (2003), op. cit., p. 89.

26 A esta materialización del vacío de Yves Klein, respondía su amigo Arman en 1960 exponiendo Lo lleno en la misma galería de Iris Clert. A menudo la historiografía artística analiza estos dos actos de manera conjunta y en oposición, en función de la concepción binaria característica del pensamiento occidental de estos conceptos - vacío y lleno - como excluyentes. Pero el vacío entendido desde el pensamiento oriental no se encuentra en oposición a lo lleno, ambos conceptos conviven facilitando la posibilidad de materializar a través del vacio la inmaterialidad del pigmento puro. 
Las relaciones entre el arte de Klein y el judo parecen terminar de hacerse visibles en una de sus últimas obras, en ese Periódico de un solo día (fig. 4) con el que el artista terminó por conquistar el vacío. “¿El pintor del espacio se lanza al vacío!”27, declara el titular que acompaña la foto del artista realizando el kata del pájaro desde una ventana. "El monocromo, que es también campeón de judo, cinturón negro $4^{\circ}$ Dan, se entrena regularmente en la levitación dinámica" 28 , continúa la siguiente línea. Klein se lanza con esta obra definitivamente al vacío, lo ha creado como una extensión de su propia persona y desaparecerá en esa idea de vacío que él mismo había proyectado. El artista buscaba en esta obra, como en el judo, esa unión del cuerpo material con lo inmaterial, la unión de lo físico y lo espiritual, la conquista a través del cuerpo del infinito.

Klein materializó con este salto ese "silencio a posteriori" que anunció poco tiempo después en el Manifiesto del Hotel de Chelsea ${ }^{29}$ y que se hizo realidad con su muerte muy poco tiempo después. En este texto, Klein revisaba toda su obra comenzando por las de los últimos años hasta llegar a la que consideró después su primera obra de arte: aquel vasto cielo azul de Niza que en 1946 hizo suyo como su primer monocromo, llegando a sentir aversión por los pájaros que agujereaban la más hermosa y grande de sus obras. Ese infinito que con tan sólo dieciocho años había conquistado y en torno al cual trabajó y meditó a lo largo de toda su vida con la intención de conquistar de manera definitiva la sensibilidad pictórica inmaterial. Klein es uno de esos artistas que no se sabe si fue pintor, escultor, arquitecto o incluso actor, ni siquiera si fue más artista que judoka; fue como señala Broucher, "un pintor involuntario" ${ }^{30}$, pintó para crear un elemento terrenal que manifestase la sensibilidad inmaterial con la intención de transportarnos más allá del estado material. Se convirtió en artista para hacer visible esa espiritualidad latente en el judo, o más bien, descubrió que siempre había sido pintor cuando halló el camino para conjugar sus proyectos artísticos con su experiencia como judoka. El Manifiesto del Hotel de Chelsea se constituye así como una especie de testamento explicativo de toda la propuesta artística de Klein que completa, con palabras, aquella primera obra de arte: Yves Peintures que no hacía sino anunciar, con imágenes y de manera un tanto enigmática, la que sería toda su propuesta artística.

Todo este misticismo y solemnidad que caracteriza la obra de Yves Klein no están reñidos en absoluto con cierta ironía también presente en todas sus propuestas artísticas. Visible claramente en aquel periódico que vendió en algunos quioscos de París anunciando su propia muerte o en aquella galería en la que ofreció al espectador el vacío. Y es que en la formación Zen, la ironía no se entiende en un sentido destructivo sino que es una vía más hacia el conocimiento. Klein no está despreciando ni burlándose del arte con estas obras, más bien ofrece otras formas de aproximación a la sensibilidad artística.

27 KLEIN, Yves (1960), op. cit., p. 1.

28 Ibid., p. 1.

29 KLEIN, Yves, "Chelsea Hotel Manifiesto" (1961), en KLEIN, Yves (2003), op. cit., pp. 291-312.

30 Vid. BROUCHER, Kerry, "Involuntary Painting", en Yves Klein: with the void full powers, catálogo de exposición (mayo-septiembre de 2010), Ostfildern, Hatje Cantz, 2010, p. 40. 


\section{Yves Peintures: el inicio de La Aventura Monocroma}

En el mes de noviembre de 1954, Klein realizó en Madrid su primera obra de arte, en la que ya se hizo visible de manera muy clara aquella sutil ironía que estará presente en toda su obra posterior. Su carrera artística comenzaba así, siendo todavía Asesor Técnico de la Federación Española de Judo, el mismo año en que publicaba en París Les Fondaments $d u J u d o^{3 l}$. Resulta esencial destacar el hecho de que en el mismo año Klein realizara dos publicaciones de naturaleza tan dispar: una gramática sobre judo y este pequeño catálogo de monocromos que debe ser considerado una obra de arte en sí misma. No es casual que se conjuguen en un mismo año y en la capital española los méritos y logros del Klein maestro de judo y las reflexiones y ensayos del Yves artista pues, a partir de este momento, estos dos caminos quedarán fusionados en la propia personalidad de Yves Klein, necesitándose siempre el uno al otro para terminar de cobrar sentido.

Yves Peintures (fig. 5) es una obra muy peculiar, se trata de una especie de folleto, muy cuidado, con un incuestionable carácter manual, compuesto por un prefacio firmado por Pascal Claude ${ }^{32}$, que tan sólo contiene líneas horizontales conformando párrafos, y diez láminas independientes, cada una de ellas con un rectángulo de un sólo color, de diversos tamaños bajo los cuales se han impreso leyendas que hacen referencia al autor, años, ciudades, medidas y en ocasiones colecciones. Klein pretendió acentuar el valor material de dicha obra destacando que se trataba de una edición limitada a 150 ejemplares y pintando con gouache la mayoría de los monocromos que en ella presentaba; el resto son papeles industriales recortados en los que el valor manual se hace visible puesto que se puede adivinar el trazo de la tijera sobre el papel. Cada uno de los ejemplares, así como las dos versiones: Yves Peintures y Haguenault Peintures, presentan sutiles diferencias que acentúan el valor único de cada obra.

Klein nos propone un viaje a través de la monocromía que coincide con los años y destinos de aquel viaje juvenil que había llegado a su fin precisamente con esta publicación. Parece como si hubiera realizado este folleto con la intención de llegar a París como un artista consagrado al que se le había dedicado incluso una publicación monográfica ${ }^{33}$. Es seguro que Klein pintó pequeños monocromos sobre papel durante estos años, los envió y mostró a sus amigos y posiblemente los colgó de las paredes del Bushidokwai en $1954^{34}$. Pero estos primeros monocromos no deberían considerarse más que pequeños ensayos, fugaces materializaciones de una idea que parecía

31 Aunque esta publicación resulta esencial para conocer la visión que tenía Yves Klein en relación con el judo, se ha preferido, por cuestiones de extensión, no abordar aquí su estudio a pesar de que la preparación de este libro está muy próxima en el tiempo a la de Yves Peintures, motivo por el cual la portada y otras cuestiones guardan similitudes formales muy destacables.

32 Se trata del nombre de su amigo Claude Pascal invertido.

33 Esta interpretación se vería apoyada por un manuscrito (inédito, Archives Yves Klein) en el que Klein describe Yves Peintures como "una recopilación de reproducciones de mis obras" y por la elección del francés como idioma para la publicación que no hace sino confirmar al público francés como claro destinatario.

34 A este respecto los datos son un tanto contradictorios. El actual director del gimnasio Macario García afirma que cuando compró el gimnasio en la década de los ochenta encontró papeles de colores (Entrevista de Irene López a Macario García, Madrid, 21 de marzo de 2011). Sin embargo, uno de los alumnos de Klein de 1954 niega haber visto ningún papel coloreado colgando de las paredes del gimnasio y afirma haberse enterado 


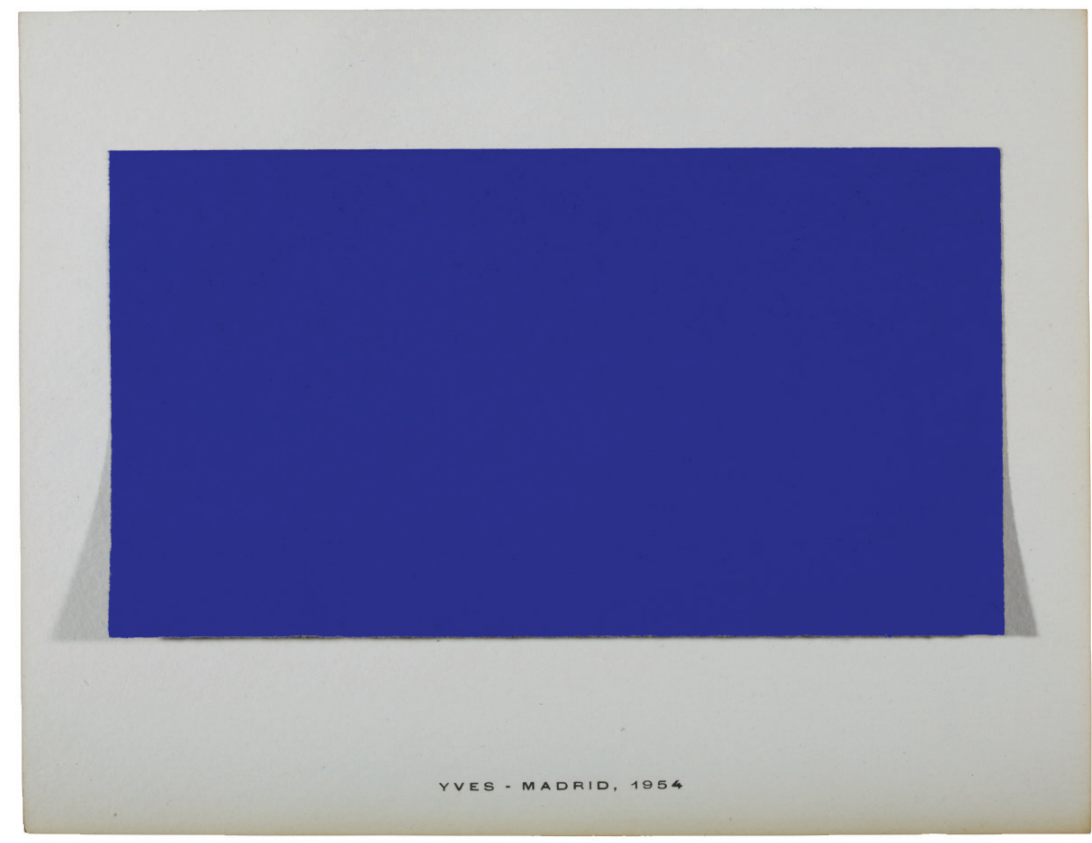

Fig. 5. Yves Klein. Yves Peintures, 1954. Planches de papier imprimées et papiers collés, 24,5 x 19 cm. C Yves Klein, Adagp, Paris, 2014.

estar rondando la cabeza de Yves Klein pero que tardaría en consolidar. En relación con los monocromos del Bushodokwai, Javier Arnaldo defiende que Klein los colgó en el gimnasio, pero en ningún caso con una intención comercial sino más bien con un sentido funcional, los empleó como "trozos de infinito, como los que el maestro judoka pensaba que debían servir de apoyo contra el adversario"35. Quedarían así conjugados, desde los inicios y en Madrid, el judo y la pintura en esta materialización tan temprana del infinito. Pero las investigaciones de Klein en torno a la monocromía se remontan todavía más, pues en aquella primera estancia de 1951, ya había planteado la idea de realizar una exposición con este tipo de obras:

"Volvimos del Café Gijón ayer por la tarde y salimos a las ocho; al paso, súbitamente empecé a referir la idea de cuadros a un solo color. Como eso parecía gustarle, le hablé de la exposición que me gustaría presentar con música apropiada; también a él todo ha parecido interesarle y preguntará noticias para una sala de exposición y músicos modernos" ${ }^{\prime 3}$.

de la incursión de Klein en el terreno artístico mucho después de que éste regresara a Francia de manera definitiva (Entrevista de Irene López a Félix Arrivas, Madrid, 4 de abril de 2011).

35 ARNALDO ALCUBILLA, Javier (2009), op. cit., p. 22.

36 Entrada del diario de Yves Klein (inédito, Archives Yves Klein), 22 de febrero de 1951, Madrid, Archives Yves Klein, segundo cuaderno, original en castellano, p. 7. 
Sin embargo, Yves Peintures es una obra mucho más compleja, pues no ilustra en ningún caso monocromos reales sino que se asienta como una obra de arte por sí misma que preludia la que será su futura propuesta artística en un tono un tanto irónico, formalmente similar al de Alphonse Allais en el Album Primo-Avrilesque ${ }^{37}$. Yves Peintures se constituye así como la llave que abrirá la puerta de acceso de esa aventura monocroma que Klein estaba a punto de iniciar, recoge cada una de las ideas en torno a las cuales había meditado a lo largo de su juventud y se establece al mismo tiempo como una declaración de intenciones. Todo ello sin quedar desprovista en ningún momento del destacado sentido material y visual que poseen todas las obras de Klein, pues es un libro más visible que legible y por tanto digno de contemplación, como lo serán los numerosos monocromos que pintará de manera continuada y que debían conducir al espectador hacia ese estado de meditación, hacia la purificación de la mirada ${ }^{38}$.

Con esta obra Klein se introdujo de lleno en ese mundo de la monocromía que terminaría por conducirle de manera natural a la conquista del vacío, del infinito. Yves Klein se preocupó a menudo de diferenciar sus propuestas monocromas (fig. 6), tal y como las denominó Restany, de la obra de Malevich que según él seguía la vía de "la exasperación de la forma ${ }^{39}$ ", en lugar de explotar las capacidades del color. Klein se ocupó a menudo de la pugna histórica entre el dibujo y el color ${ }^{40}$. "Los colores solos habitan el espacio y la línea simplemente viaja, lo surca. La línea atraviesa el infinito mientras que el color lo es" ${ }^{41}$, defendía el artista. De este modo, el color y sus incuestionables capacidades materiales, sugestivas y vitales parecerían entrar en contradicción con el matiz espiritual del planteamiento artístico de Klein. Sin embargo, el artista se situó siempre en el bando del color: "los colores son seres vivos, individuos, [...] son los verdaderos habitantes del espacio" ${ }^{42}$, declaraba. Con esta sustancia

37 Se trata de una obra del humorista Alphonse Allais publicada en 1897 cuyas similitudes formales con la obra de Klein son muy destacables pues se compone de siete láminas de colores monocromos con títulos descriptivos muy irónicos y de la partitura de una marcha fúnebre para las exequias de un hombre sordo que muestra las líneas del pentagrama en blanco. No está claro si Klein conoció la obra de Allais pues Claude Pascal negó mucho tiempo después que Klein la hubiera visto jamás, a pesar de que Allais gozaba de gran popularidad entre el público francés y de que ese mismo año era el centenario de su nacimiento. Se trata de dos publicaciones en tonos algo diferentes pero en las que la ironía, la ambigüedad, el enigma y el silencio parecen rasgos comunes. Klein, a través del lenguaje artístico, subvierte con su publicación los principios del arte del mismo modo en que Allais con un tono humorístico, adivina los derroteros y agotados lugares a los que llegará el arte casi un siglo después.

38 Vid. ALLAIN, Bernadette, "Propositions Monochromes du peintre Yves", Couleurs, no 18, diciembre de 1956, en OTTMANN, Klaus (2010), op. cit., p. 419: "Sus monocromos tenían una existencia propia, pretendían crear una atmósfera particular, [...] invitar a la meditación. Así, cada cuadro de Yves creaba su propio universo".

39 KLEIN, Yves, "L'aventure Monochrome: L'épopée monochrome", en KLEIN, Yves (2003), op. cit., p. 258.

40 En relación con este tema Klein escribió un borrador de guión cinematográfico (inédito, Archives Yves Klein), "La guerre (de la ligne et de la couleur) ou (vers la proposition monochrome)" (1954), que publicó en forma de texto en Dimanche. Le Journal d'un seul jour (1960), con el título de "La guerre".

41 KLEIN, Yves, "Ma position dans le combat entre la ligne et la couleur" (1958), en KLEIN, Yves (2003), op. cit., p. 49.

42 KLEIN, Yves, “L’aventure monochrome: L'épopée monochrome”, en KLEIN, Yves (2003), op. cit., p. 229. 


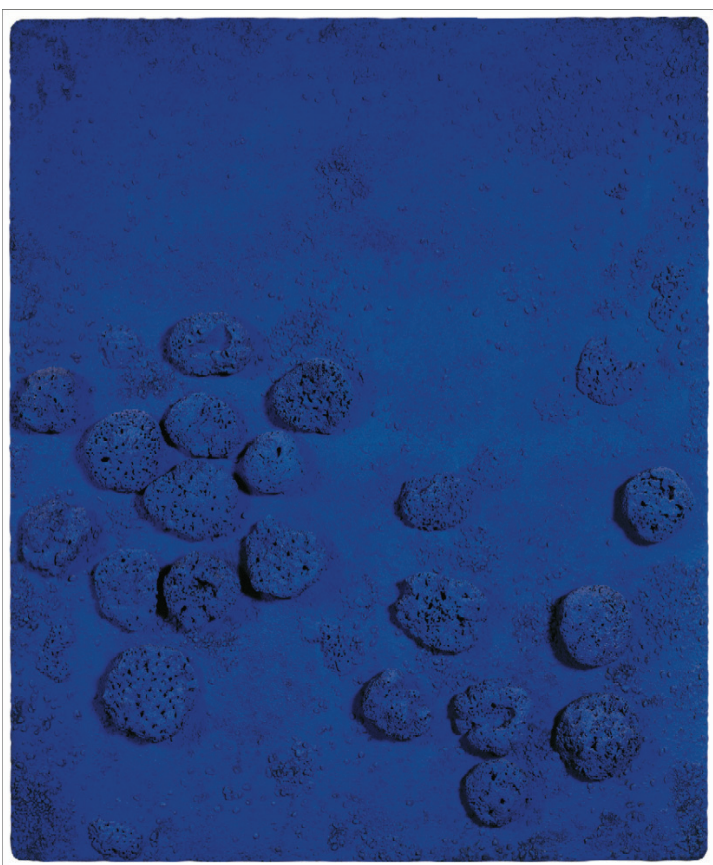

Fig. 6. Do-do-do, (RE 16), 1960. Pigment pur et résine synthétique, éponges naturelles, cailloux sur panneau, 199 x 165 x 18 cm (C) Yves Klein, Adagp, Paris, 2014.

viva, Klein materializó la sensibilidad en estado puro. Color, pues, como sustancia vital en sí misma, como la sangre que da vida al entramado del lienzo. Así comparaba el futuro artista el color y la sangre en un poema que le dedicó a España:

"Un día el cielo azul sobre la tierra ha caído /y de su herida la sangre ha brotado.

Era rojo brillante chispeando y estrepitoso, / había negro también allí donde se coagulaba.

Una bolsa de sangre que era España. / El azul la ha ampollado, muy pálido.

Cuando se miraban había relámpagos violados. / La música era celos

y en la paz del Azul reinaba la cólera del Rojo.

España divina dolor y rojo [sic.]"43

Sangre y color como materia que encarna la vida en el cuerpo y en el cuadro. Carnalidad era lo que Cézanne reclamaba a la pintura en aquel famoso paseo por el Louvre que dio en compañía de Gasquet ${ }^{44}$, y carnalidad fue lo que Klein aportó con sus antropometrías a la pintura; carnalidad por medio de la sangre del $\mathrm{IKB}^{45}$ con

43 Entrada del diario de Yves Klein (inédito, Archives Yves Klein), 27 de febrero de 1951, Madrid, segundo cuaderno, original en castellano, p. 14. El poema aparece también escrito en francés en una página del primer cuaderno, prácticamente idéntico a la versión española a diferencia de algunos detalles y de la ausencia del último verso.

44 Vid. GASQUET, Joaquim, “Le Louvre”, en Cézanne (1921), Dijon, Cynara, 1988, p. 159-188.

45 International Klein Blue. 
el que pintaban aquellas mujeres. "La sangre de la sensibilidad es azul", repetía a menudo Yves Klein ${ }^{46}$; fue esa misma sangre la que suministraron las mujeres a la pintura, y con ella el artista logró impregnar la obra de esa espiritualidad inmaterial que había conquistado a través de la distancia, a través de ese vacío intermedio que había establecido con la obra. Klein conquistó con materia viva en estado puro, la espiritualidad en sí misma; materializó ese infinito en sus obras logrando hacer del color el eterno y definitivo vencedor en ese combate histórico que la línea y el color han venido manteniendo a menudo.

Klein exige la presencia activa del espectador en cada una de sus obras, sólo mediante esa presencia logrará alcanzar ese mismo estado de liberación al que se llega mediante la meditación. Propondrá en cada uno de sus monocromos, en los que el pigmento puro parece el elemento fundamental, un baño de color, "una ventana abierta a la libertad de impregnarse de manera infinita y sin límite en el estado del color inconmensurable, una posibilidad de iluminación de la materia pictórica" ${ }^{47}$. Vuelven a conjugarse así el cuerpo y el espíritu, lo material y lo etéreo, en esta experiencia monocroma mediante esa demanda activa del espectador en ese acto de impregnación.

Yves Peintures recopilaba las reflexiones juveniles de Klein en torno al color y sentaba además las bases de la monocromía que comenzaría a desarrollar inmediatamente después. El vacío y el silencio, dos caminos hacia el infinito, se hacen presentes en esta primera obra, material e inmaterial al mismo tiempo puesto que a través de su propia materialidad pone de relieve la inmaterialidad de las obras que ilustra. Klein inauguraba su aventura monocroma con esta obra y parecía clausurarla con aquella materialización del Vacio de 1958 cargado de la inmaterialidad del azul, vacío en el que la sangre de la sensibilidad circulaba y con el que Klein llegó al "estado superior de la aventura monocroma" ${ }^{48}$. De este modo, publicando Yves Peintures y autoimponiéndose el nombre de Yves le monochrome, Klein había decidido materializar la monocromía en su propia persona.

Yves Klein concibió cada una de sus propuestas artísticas como una reflexión que terminaría de tomar forma en la obra siguiente y así debe entenderse su primera obra, como una especie de manifiesto que materializa, a priori, una compleja propuesta artística que no perderá jamás la coherencia. "Mis cuadros monocromos no son mis obras definitivas sino la preparación a mis obras; son los restos de la actividad creadora, las cenizas" ${ }^{49}$, escribía Klein. Del mismo modo debemos entender Yves Peintures, como las primeras cenizas de esa reflexión artística que conformará los cimientos de toda su propuesta futura. Esta primera obra proyecta el camino que Klein va a seguir por el ámbito artístico, camino suave y flexible que resultará siempre fácil

46 Vid. KLEIN, Yves, "L'évolution de l'art vers l'immatériel. Conférence à la Sorbonne" (1959), en KLEIN, Yves (2003), op. cit., p. 122.

47 KLEIN, Yves, "L'aventure Monochrome: L'épopée monochrome", en KLEIN, Yves (2003), op. cit., pp. 245-246.

48 RESTANY, Pierre, Une minute de verité (1956), texto escrito con motivo de la exposición Propositions Monochromes, Galerie Colette Allendy, Paris, 1956, en RESTANY, Pierre, Yves Klein. Le monochrome, Paris, Hachette, 1974, p. 56.

49 KLEIN, Yves, “Comment et pourquoi”, en OTTMANN, Klaus (2010), op, cit., p. 69. 
de recorrer, pues sienta sus bases sobre los fundamentos del judo, los mismos que ya habían sido planteados, con absoluta madurez, en esta primera obra.

Yves Peintures se establece como una peculiar obra de arte en la que quedan conjugados el maestro de judo y el artista. Fue en Madrid donde el arte y el judo terminaron por fusionarse. Y no volverían a separarse jamás llevando a Klein a hacer, de su propia vida, su mayor obra de arte a través de cada una de las innovadoras propuestas artísticas en las que participaba activamente, aportando un poco de su vida, de su propio cuerpo y de su espíritu, al igual que en los combates de judo. Siguiendo este lema Klein terminó por lanzarse al vacío fundiéndose, él mismo, con la sensibilidad pictórica inmaterial, con el arte mismo. Todo aquel que comprara el Periódico de un solo día aquel domingo de 1960 creería que había llegado el verdadero fin de la actividad artística de Klein. Y de un modo similar, cuando Klein murió en 1962 con tan sólo treinta y cuatro años, su amigo Jouffroy llegó a pensar que se trataba de otra de sus puestas en escena, de esas que desde hacía siete años venía realizando siguiendo el guión anunciado en Yves Peintures. El judo se fundió en Madrid con el arte de Klein y finalmente el arte lo hizo con su propia vida. Klein lo defendió siempre: "la vida, la vida misma es el arte absoluto" ${ }^{50}$.

\section{Conclusión}

La ciudad de Madrid se establece de este modo como un lugar clave en la gestación artística de Yves Klein. Fue en esta ciudad donde el judo y su arte terminaron por fusionarse. Esta unión comenzó en la imprenta de un judoka con una obra de arte cargada de misterios. Una obra en la que quedó materializada esa concepción homogénea del espacio y del tiempo que tiende hacia el infinito, ese tiempo en el que terminaría por no haber ni pasado ni futuro, sino simplemente un presente continuo. Yves Peintures es un catálogo retrospectivo de una obra que aún está por llegar, ilustra los fundamentos de una propuesta artística que, puesto que es todavía inexistente, no hace sino remitir al futuro. Confundiendo pasado, presente y futuro, Yves Peintures sugiere ese infinito que Klein se esforzó siempre por conquistar.

El judo pretende que el pensar siga al sentir hasta que el sentimiento pueda mover el cuerpo ${ }^{51}$, y para Klein el arte debería pretender esto mismo, hacer vibrar físicamente el cuerpo a través de la experiencia estética. De este modo Klein propuso con vehemencia la conquista del infinito y de la espiritualidad a través de las sensaciones, la inmersión del cuerpo físico del espectador en un espacio más vasto que el infinito, en el arte mismo, material por naturaleza. Klein conjugó a lo largo de toda su obra principios aparentemente contradictorios como lo sensorial y lo espiritual, lo material y lo infinito. Lo hizo siguiendo las bases del pensamiento oriental en el que conceptos

50 KLEIN, Yves, “Discours prononcé à l'occasion de l'Exposition de Tinguely à Düsseldorf” (1959), en KLEIN, Yves (2003), op. cit., p. 103.

51 GODET, Robert J., Tout le judo: son histoire, sa téchnique, sa philosophie, cit. en STICH, Sidra, Yves Klein, catálogo de exposición, mayo-agosto 1995, Madrid, Museo Nacional de Arte Reina Sofía, Ostfildern, Cantz, 1994, p. 39. 
como el vacío y la plenitud no son contrarios sino complementarios. Siguiendo este complejo planteamiento, Klein logró materializar por medio de sus obras de arte la espiritualidad, el infinito, el silencio y el vacío mismo. 